\title{
Mutations in the Promoter Region of the Gene for gp91-phox in X-linked Chronic Granulomatous Disease with Decreased Expression of Cytochrome $b_{558}$
}

\author{
Peter E. Newburger, ${ }^{\star}$ David G. Skalnik, ${ }^{\ddagger}$ Penelope J. Hopkins, ${ }^{\mathbf{5}}$ Elizabeth A. Eklund, ${ }^{\star}$ and John T. Curnutte \\ * Departments of Pediatrics and Molecular Genetics/Microbiology, University of Massachusetts Medical School, \\ Worcester, Massachusetts 01655; ${ }^{\ddagger}$ Herman B Wells Center for Pediatric Research and Department of Pediatrics, \\ Indiana University Medical Center, Indianapolis, Indiana 46202-5225; and ${ }^{\S}$ Department of Molecular and \\ Experimental Medicine, The Scripps Research Institute, La Jolla, California 92037
}

\begin{abstract}
We examined the molecular defect in two kindreds with "variant" X-linked chronic granulomatous disease (CGD). Western blots of neutrophil extracts showed decreased immunoreactive cytochrome $b_{558}$ components gp91-phox and p22-phox. Analysis of mRNA demonstrated reduced gp91phox transcripts, with relative preservation of an alternative mRNA species created by transcription initiation in the third exon of the gene. Single strand conformation polymorphism analysis of the 5 ' flanking region of the patients' gp91-phox genes revealed an electrophoretic abnormality not detected in 40 other gp91-phox genes. Genomic sequencing demonstrated a single base change associated with CGD in each kindred: in one, adenine to cytosine at base pair 57 and in the other, thymidine to cytosine at -55 . These mutations are located between the "CCAAT" and "TATA" box consensus sequences involved in eukaryotic gene transcription. Gel shift assays revealed two specific DNA-protein complexes formed between phagocyte nuclear extracts and an oligonucleotide probe representing bases -31 to -68 of the gp91-phox promoter region; the fastermigrating complex could not be formed with oligonucleotides containing either of the promoter mutations. Thus, these promoter region mutations appear to be causally related to the loss of association of a DNA-binding protein and lead to diminished gp91-phox expression, abnormal transcription initiation, and the development of CGD. ( $J$. Clin. Invest. 1994. 94:1205-1211.) Key words: DNA-binding proteins - gene expression regulation - phagocytes • hereditary diseases $\cdot$ point mutation
\end{abstract}

This work has been presented in part at the meeting of the American Society of Hematology, Anaheim, CA, 4-7 December 1992 [1992. Blood. 80(Suppl. 1):251a].

Address correspondence to Peter E. Newburger, MD, Department of Pediatrics, University of Massachusetts Medical School, Worcester, MA 01655. P. J. Hopkins' present address is San Diego Regional Cancer Ctr., San Diego, CA 92121. E. A. Eklund's present address is University of Alabama at Birmingham, Birmingham, AL 35293. J. T. Curnutte's present address is Department of Immunology, Genentech, Inc., South San Francisco, CA 94080.

Received for publication 24 February 1994 and in revised form 2 June 1994.

J. Clin. Invest.

(C) The American Society for Clinical Investigation, Inc. 0021-9738/94/09/1205/07 \$2.00

Volume 94, September 1994, 1205-1211

\section{Introduction}

Chronic granulomatous disease (CGD) ${ }^{1}$ is an uncommon hereditary disorder characterized by recurrent pyogenic infections which usually present early in life and may lead to death in childhood (1-4). Phagocytes from CGD patients display normal chemotaxis, ingestion, and degranulation; but microbial killing is deficient (5). The underlying biochemical defect is the failure of a membrane-associated NADPH oxidase to produce superoxide and related toxic oxygen metabolites $(6,7)$.

The phagocyte NADPH oxidase contains a low-midpointpotential $b$-cytochrome as the terminal electron donor. This heme protein, cytochrome $b_{558}$, is a heterodimer of a $91-\mathrm{kD}$ glycoprotein component of the phagocyte oxidase (gp91-phox) and a 22-kD nonglycosylated polypeptide ( $\mathrm{p} 22-$ phox $)(8)$. The gene for gp91-phox was one of the first to be identified by positional cloning (9) following localization to $X$ chromosome band Xp21.1 (10). Hence, CGD kindreds with the gp91-phox component affected show $X$-linked inheritance $(11,12)$ and in most cases the cytochrome $b_{558}$ is reduced or absent from their phagocytes (13).

The gene encoding gp91-phox encompasses 13 exons spanning $\sim 30 \mathrm{~kb}$ of human $\mathrm{X}$ chromosome genomic DNA (14). Multiple molecular defects producing X-linked CGD have been identified within the coding region and introns of the gene (1521 ). Such mutations include large, multigene deletions, smaller deletions and insertions, missense and nonsense substitutions, and splicing defects. In $58 \%$ of X-linked CGD kindreds ( 28 of 48 tested), phagocytes express diminished levels of gp91-phox mRNA (Curnutte, J. T., and P. E. Newburger, manuscript in preparation.); yet, for most such patients, no molecular defects have been identified in PCR-amplified genomic DNA encoding gp91-phox gene exons (J. T. Curnutte, P. J. Hopkins, and P. E. Newburger, unpublished data).

We have recently identified two kindreds with an unusual form of X-linked CGD (22) and reported in detail the clinical and biochemical characteristics of their phagocytes. ${ }^{2}$ In the majority of patients with CGD, phagocytes completely lack cytochrome $b$ and exhibit no detectable oxidase activity. Occasional, "variant" forms of X-linked CGD occur, in which low levels ( $1-25 \%$ of normal) of cytochrome $b$ and proportionately decreased oxidase activity are expressed uniformly in all phago-

\footnotetext{
1. Abbreviations used in this paper: CGD, chronic granulomatous disease; gp91-phox, $91 \mathrm{kD}$ glycoprotein component of the phagocyte oxidase; p22-phox, $22 \mathrm{kD}$ protein component of the phagocyte oxidase; RACE, rapid amplification of cDNA ends; SSCP, single strand conformation polymorphism.
} 
cytes (23-27). However, in the two kindreds of the present study, a small subset $(5-10 \%)$ of neutrophils expressed near normal levels of cytochrome $b$ and oxidase activity, while the remaining cells completely lacked both. Hence the pooled cell oxidase activity was $5-10 \%$ of normal, as seen in other forms of "variant" CGD, but the cellular distribution was distinctly different. X-linked inheritance was established by maternal carrier testing. Cytogenetic and restriction fragment length polymorphism analysis demonstrated $\mathrm{X}$ chromosome hemizygosity and thus ruled out a sex chromosome abnormality with random $\mathrm{X}$ chromosome inactivation as a cause for the observed distribution of activity. Thus, we hypothesized a genetic defect in gp91phox gene regulation as the cause for this form of CGD.

We have investigated the molecular basis of this apparent defect in the regulation of gp91-phox expression, and now report two neighboring mutations in the upstream promoter region of the gp91-phox gene in these kindreds. Both mutations prevent the association of an unidentified DNA-binding protein with oligonucleotide sequences from the promoter region. The functional consequences of the promoter region mutations are impaired transcription of the gp91-phox gene and utilization, at a decreased rate, of an alternative downstream transcription start site.

\section{Methods}

Subjects. The clinical and biochemical characterization of the CGD patients reported in this study have been previously reported in abstract form $(22,28)$ and in detail elsewhere. ${ }^{2}$

Procedures and consent forms were approved by the Committees on the Protection of Human Subjects in Research of the University of Massachusetts Medical Center and The Scripps Research Institute.

Western blots. Immunoreactive quantitation of gp91-phox and p22phox in diisopropylfluorophosphate-treated granulocyte extracts was performed by Western blotting, using previously reported antisera and methodology $(29,30)$. Extracts were prepared from the membrane fraction of Percoll gradients (31) and $10 \mathrm{mg}$ from each sample used per lane for polyacrylamide gel electrophoresis.

Northern blots. Mixed mononuclear cells were isolated from citrateanticoagulated whole blood by ficoll-hypaque centrifugation (32). Total cell RNA was extracted from the cells by the guanidine- $\mathrm{HCl}$ method (33) and analyzed by Northern blots performed according to standard procedures (34). Hybridization probes were full-length cDNAs for the human gp91-phox (9), p22-phox (35) (kindly provided by Dr. M. Dinauer, Indiana University Medical Center). Procedures for sequential cycles of prehybridization, hybridization, washes, and filter stripping were performed as described by Gatti, Concannon, and Salser (36). Equal loading of lanes was demonstrated by examination of gels after ethidium bromide staining and by rehybridization with a 5.8-kb HindIII restriction fragment of rat 18 S ribosomal DNA (37).

Band densitometry was performed by computer image analysis of the integrated optical density of autoradiograph bands, using ImageMeasure software (Microscience, Inc., Federal Way, WA) on an Epson Equity III + computer, or by direct measurement of ${ }^{32} \mathrm{P}$ decay on a Betascope 603 (Betagen, Waltham, MA) blot analyzer.

Single-strand conformation polymorphism (SSCP) analysis. Genomic DNA was extracted from peripheral blood (34) and analyzed by SSCP as previously described $(38,39)$ using two-stage nested primer PCR with outer 20-bp oligonucleotide primers with $0.1 \mu \mathrm{g}$ of genomic DNA, then inner primers end-labeled with ${ }^{32} \mathrm{P}$ with the first PCR products as template. The resultant labeled PCR products were visualized by polyacrylamide gel electrophoresis and autoradiography. SSCP analysis was performed on the $5^{\prime}$ flanking region and all 13 exons of the gp91-phox gene.

$5^{\prime}$ end mapping of mRNA transcripts. We adapted the reagents and procedures from the Clontech, Inc. (Palo Alto, CA) 5'-AmpliFINDER $^{\text {TM }}$ RACE (rapid amplification of cDNA ends) Kit (40, 41 ). The basic strategy was to prepare B cell line polyadenylated RNA (34), reverse transcribe from a primer specific to gp91-phox nucleotides 600 634 , anneal an anchor to the $5^{\prime}$ end of the resultant cDNA by singlestranded ligation with T4 RNA ligase in the presence of hexamine cobalt chloride (42), and then PCR amplify the ligation product using an anchor-specific forward primer and successive nested reverse primers corresponding to nucleotides 417-434 and 375-405. The PCR products were analyzed by agarose gel electrophoresis and sequenced after subcloning into pBluescript (Stratagene, La Jolla, CA).

DNA sequencing. Genomic DNA was isolated from peripheral blood leukocytes by standard methods (34) and amplified by PCR using synthetic oligonucleotide primers designed to amplify the 5 '-flanking region or each of the first 12 (coding region) exons of the gp91-phox gene. Alternatively, coding region segments were amplified from cDNA prepared by reverse transcription (Pharmacia First-Strand cDNA Synthesis Kit; Pharmacia Fine Chemicals, Piscataway, NJ) of mononuclear cell RNA, prepared as above. Amplified segments were subcloned into pUC19 or related plasmids and bidirectional dideoxy sequencing of the double-stranded DNA was performed by standard methods (34).

DNA sequence data were repetitively confirmed by sequencing the same segments of DNA in different laboratories (Scripps and University of Massachusetts) using different PCR primers.

Gel shift assays. The myelomonoblastic PLB985 cell line (43) was the generous gift of Thomas Rado (Department of Medicine, University of Alabama at Birmingham). These cells were grown in RPMI medium supplemented with $10 \%$ fetal calf serum, $0.2 \mathrm{mM}$ glutamate, $50 \mathrm{U} / \mathrm{ml}$ penicillin, and $50 \mu \mathrm{g} / \mathrm{ml}$ streptomycin. Differentiation of PLB985 cells along the granulocytic lineage was performed by the addition of 1 $\mu \mathrm{M}$ retinoic acid for $24 \mathrm{~h}$ followed by $60 \mathrm{mM}$ dimethylformamide for $24 \mathrm{~h}$.

Nuclear extracts were prepared as described by Dignam et al. (44). Complementary oligonucleotides were annealed and end-labeled with $\left[\gamma-{ }^{32} \mathrm{P}\right]$ ATP as previously described (14). All oligonucleotides were synthesized so that annealed strands contain BamHI overhangs at their ends. Gel shift assays were carried out by adding nuclear extract (3-5 $\mu \mathrm{g}$ ) to $18 \mu \mathrm{l}$ of buffer [10 mM Tris ( $\mathrm{pH} \mathrm{7.5),} 50 \mathrm{mM} \mathrm{K}$-glutamate, 5 $\mathrm{mM} \mathrm{MgCl}_{2}, 1 \mathrm{mM}$ dithiothreitol, $1 \mathrm{mM}$ EDTA, 5\% glycerol, $50 \mathrm{mM}$ poly $[\mathrm{d}(\mathrm{IC})]$, and competitor double-stranded oligonucleotides where indicated ], and the mixture was preincubated on ice for $15 \mathrm{~min}$. Approximately 5-10 $\times 10^{3} \mathrm{dpm}$ of probe was then added to each sample and incubation on ice was continued for $15 \mathrm{~min}$. Samples were loaded onto a $0.5 \times$ TBE [ $45 \mathrm{mM}$ Tris ( $\mathrm{pH} 8.3$ ), $45 \mathrm{mM}$ borate, $1.25 \mathrm{mM}$ EDTA], $3.5 \%$ nondenaturing polyacrylamide gel, and electrophoresis was carried out at $4^{\circ} \mathrm{C}$ until the free probe was at the bottom of the gel. Gels were then dried and autoradiography was performed.

\section{Results}

We studied one patient (here designated $P$ ) from one kindred and two brothers (designated $B 1$ and $B 2$ ) from another, unrelated kindred with an unusual form of CGD with low levels of residual oxidase activity (22). The clinical and biochemical characterization of these CGD patients are reported in detail elsewhere. $^{2}$

To investigate levels of cytochrome $b_{558}$ protein components, we examined western blots of neutrophil extracts, illustrated in Fig. 1. Normal neutrophils (lanes 1,4 , and 8 ) contained both gp91-phox $(a)$ and p22-phox $(b)$; whereas cytochrome $b$ negative CGD neutrophils (lanes 2 and 7) contained neither. In CGD patients $\mathrm{P}, \mathrm{B} 1$, and $\mathrm{B} 2$ (lanes 3, 5, and 6, respectively),

2. Woodman, R. C., P. E. Newburger, P. Anklesaria, M. S. Cohen, and J. T. Curnutte, manuscript submitted for publication. 


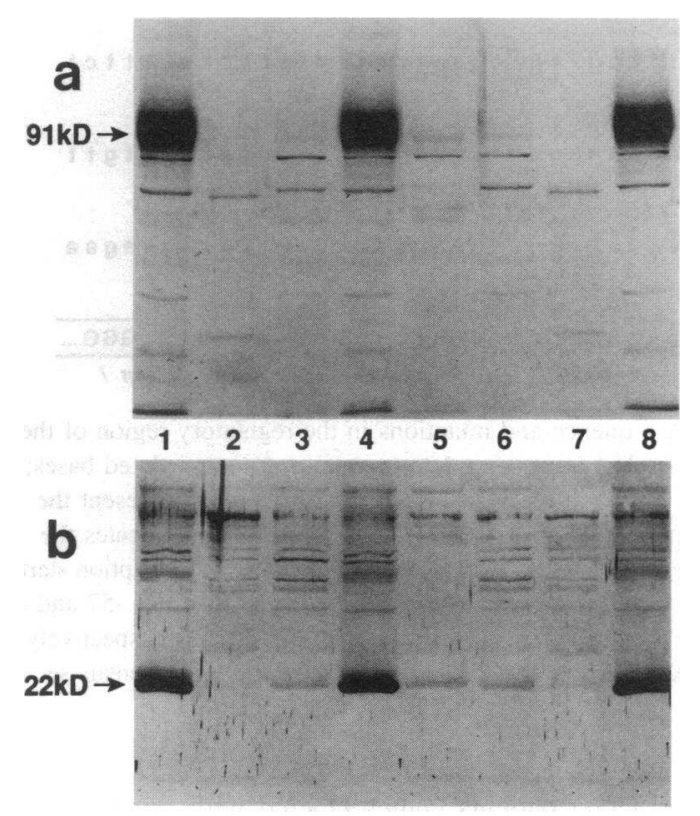

Figure 1. Western blot of immunoreactive gp91-phox and p22-phox protein. Lanes 1, 4, and 8: Neutrophil extracts from normal donors; lanes 2 and 7, from cytochrome $b$-negative CGD patients; lane 3, from patient $\mathrm{P}$; lane 5 , from patient $\mathrm{B} 1$; lane 6 , from patient $\mathrm{B} 2$. (a), Neutrophil extracts probed with antibody against gp91-phox, detected as a wide band at the indicated position. $(b)$, Neutrophil extracts probed with antibody against p22-phox, detected at the indicated position. 10 $\mu \mathrm{g}$ protein loaded per lane.

neutrophils showed markedly decreased, but detectable, levels of immunoreactive gp91-phox and p22-phox. These results indicate that the patients have a cytochrome $b$ negative form of CGD, with slight retention of immunoreactive cytochrome components consistent with the low residual oxidase activity in the cells. However, deficiency of either cytochrome component destabilizes the other member of the heterodimer (45), so the Western blot results are equally consistent with an X-linked defect in the gene encoding gp91-phox production or with autosomal mutations in both alleles of the p22-phox gene.

Northern blot analysis demonstrated the levels of gp91-phox mRNA transcripts in the patients' and normal peripheral blood mononuclear cells. As shown in Fig. 2 a gp91-phox expression was reduced in the patients' cells, compared to the normal control lane at the far right. The Northern blot hybridization of full length gp91-phox cDNA probe to each patient's RNA showed a relative preservation of a slightly more rapidly migrating transcript that is usually overshadowed by the predominant larger 4.7-kb band in RNA from normal phagocytes. It is best illustrated in autoradiograph in Fig. $2 b$, which represents a Northern blot of RNA analyzed by long duration, low voltage electrophoresis in an $\mathbf{0 . 8 \%}$ agarose-formaldehyde gel to maximize separation of the two bands.

All three patients' mononuclear cells expressed normal levels of mRNA for p22-phox, the other component of the cytochrome $b_{558}$ heterodimer, shown in Fig. 2. HeLa cell RNA, which served as a negative control for gp91-phox expression, demonstrates transcripts for $\mathrm{p} 22-$ phox, which is expressed in a wide variety of nonphagocytic cells (35).

In order to investigate the nature of the shorter transcript that was preferentially expressed in the CGD cells, we amplified

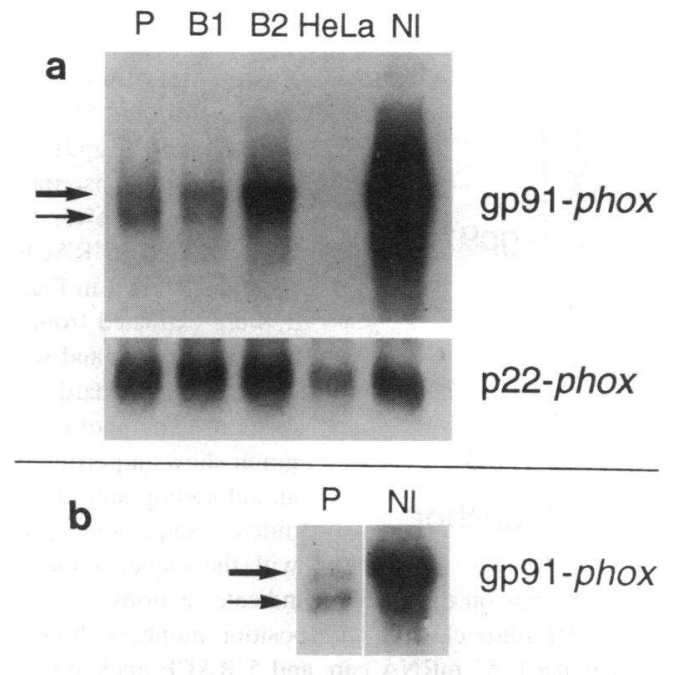

Figure 2. Northern blot of gp91-phox and p22-phox mRNA transcripts. Each lane contained $10 \mu \mathrm{g}$ total cellular RNA from peripheral blood mononuclear cells of the indicated donors or HeLa cell cultures, as indicated. $a$ shows a blot probed with ${ }^{32} \mathrm{P}$-labeled full length gp91-phox cDNA, then stripped and reprobed with p22-phox cDNA. $b$ shows a similar blot, probed only for gp91-phox transcripts, of a gel run under conditions (see text) designed to maximize resolution of the two transcript sizes. The thick arrows indicate the position of the normally predominant, larger transcript; the thin arrows indicate the normally minor, smaller transcript.

segments of cDNA produced by reverse transcription of RNA from each patient. We utilized lymphoblastoid B cell lines created by Epstein-Barr virus infection of the patients' peripheral blood lymphocytes in order to harvest enough RNA for purification of the polyadenylated RNA fraction, which is enriched in messenger RNA. B cell lines from normal individuals express phagocyte oxidase activity; but those derived from CGD patients show biochemical and molecular defects similar to those of the patients' phagocytes (46). Thus, they can serve as in vitro models of CGD cells and as sources for large harvests of CGD patient nucleic acid. We confirmed that Northern blots from these cells showed the same pattern of gp91-phox expression as that observed from fresh peripheral blood mononuclear cells (data not shown). All PCR products from primers corresponding to the gp91-phox cDNA sequence were normal in size. We next amplified the 5' ends of the transcripts by utilizing a forward primer corresponding to an anchor annealed to the 5 ' end of each cDNA. The resultant products, shown in Fig. 3, demonstrated that an alternative transcript, $\sim 200$ bp shorter than normal, was expressed along with the normal product in B cell lines from each kindred. The shorter product, which was

Figure 3. 5' ends of gp91-phox mRNA transcripts. 5'RACE PCR products of gp91-phox transcripts from the normal $(N l)$ or CGD ( $P$ and $B 2)$ B cell lines were electrophoresed in a $3 \%$ agarose gel and stained with ethidium bromide. The right margin indicates the positions of DNA size markers run in parallel.

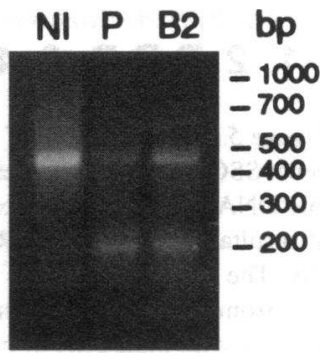




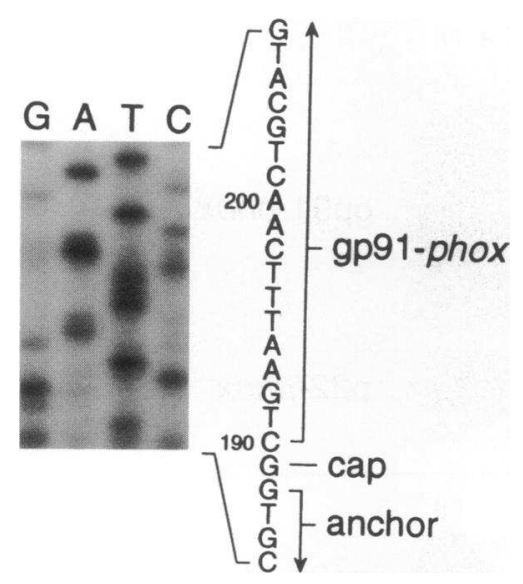

Figure 4. cDNA sequence from the 5 ' end of CGD patient gp91phox mRNA transcript. DNA from the lower bands of CGD 5'RACE products, shown in Fig. 3 , were extracted from gels, subcloned, and sequenced by standard methods. The photograph shows a portion of an autoradiograph of a dideoxy sequencing gel, with the sequence indicated on the right. Notations on the far right indicate sections corresponding to normal gp91-phox cDNA (with position numbers shown to the left of the sequence), 5' mRNA cap, and 5'RACE anchor sequences.

barely detectable in normal cells, appeared at greater or equal proportion to the normal product in the patient samples. These results were confirmed by 5 ' RACE analysis of whole cell RNA extracts from peripheral blood mononuclear cells.

Sequencing of the short PCR products showed, as in the example presented in Fig. 4, gp91-phox sequence starting at nucleotide 190 , then a guanine residue, followed by the ligated anchor sequence. This finding indicates that transcription of this mRNA species began at an alternative initiation site (cDNA nucleotide 190) within the third exon of the gp91-phox gene and was normally capped with a guanine residue at the 5' end (47). Some 5'RACE amplifications from members of each kindred also produced a less abundant, shorter product beginning at cDNA nucleotide 255 , also within the third exon.

To determine whether mutations in the regulatory region of the gp91-phox gene could be responsible for its diminished expression in these patients, we screened the $5^{\prime}$ (upstream) flanking region of the gene by single strand conformation polymorphism (SSCP) analysis of PCR-amplified genomic DNA. As shown in Fig. 5, single strand electrophoretic mobility of this segment of gp91-phox genes from patients B1 and B2, but not $\mathrm{P}$, differed from normal (lane $N$ ) and from patterns seen in

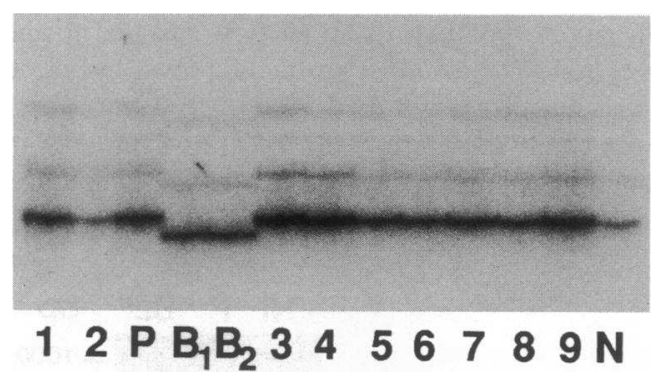

Figure 5. SSCP analysis of the 5' flanking region of the gp91-phox gene. SSCP analysis was performed, as described in Methods, on genomic DNA extracted from peripheral blood leukocytes. The gel mobility of resultant ${ }^{32} \mathrm{P}$-labeled PCR products was visualized by autoradiography. The lanes represent, as indicated on the lower margin, SSCP products from patients $\mathrm{P}, \mathrm{B} 1$, and $\mathrm{B} 2$; normal donors (N); and nine CGD patients with mutations in other regions of the gp91-phox gene (1-9).

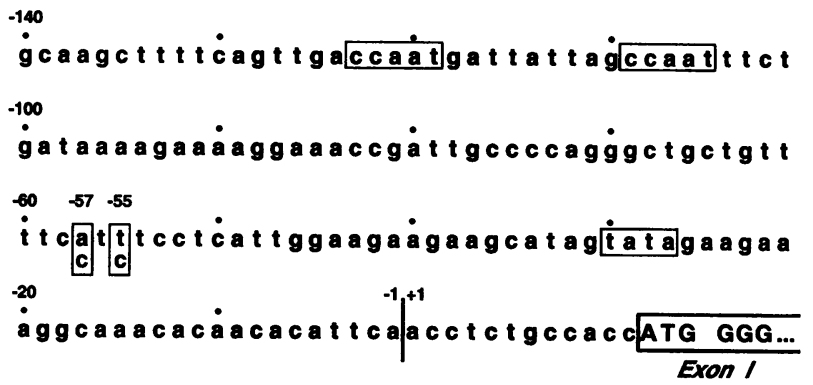

Figure 6. DNA sequence and mutations in the regulatory region of the gp91-phox gene. The lower case letters represent nontranslated bases; the upper case letters in the bold box at the lower right represent the first two codons of the open reading frame. Numbering indicates the position $5^{\prime}$ (negative numbers) or $3^{\prime}$ (positive) to the transcription start site (indicated by a vertical line). Vertical boxes at positions -57 and 55 indicate the base changes found in the $B$ and $P$ families, respectively. Horizontal boxes indicate the CCAAT and TATA box consensus sequences.

other X-linked CGD patients (lanes labeled with numbers 19 ). The SSCP abnormality was not detected in any of 40 other normal gp91-phox genes; thus the B family mutation was associated with the CGD phenotype of these kindreds and did not appear to be a commonly occurring polymorphism of the gp91phox gene. The normal pattern in patient $\mathrm{P}$ does not necessarily imply a normal sequence in the $5^{\prime}$ flank, since not all base changes result in alterations of SSCP mobility. We therefore examined the region in more detail by DNA sequencing.

Genomic sequencing demonstrated a single base change associated with CGD in each kindred: in patient $B$, adenine to cytosine at base pair -57 (i.e., 57 bp upstream from the transcription site); and in family $P$, thymidine to cytosine at base pair 55 (indicated in Fig. 6). These closely adjoining mutations are located in between the "CCAAT box" consensus sequences and a partial "TATA box" element (see Discussion) that serve as recognition sites for DNA-binding proteins essential for the transcription of gp91-phox (14) as well as myriad other eukaryotic genes (48). Examination of all 13 exons of the gp91-phox gene by SSCP and DNA sequencing did not reveal any coding region abnormalities in the patients.

Gel shift assays were performed to determine directly whether the gp91-phox promoter mutations identified in these CGD patients affect interactions with DNA-binding proteins. Fig. 7 shows that two specific DNA/protein complexes (indicated by arrows) are formed when a 39-nucleotide region of the gp91-phox promoter region ( -30 to -68$)$ is used as a probe and mixed with nuclear extract isolated from PLB985 cells (lane 2). These two bands are specific, as they are eliminated by competition with an $\sim 100$-fold excess of unlabeled doublestranded homologous oligonucleotide (lane 3), but are unaffected by the addition of heterologous oligonucleotide (lane 4). Importantly, the faster migrating of these two complexes (solid arrow) is abolished when oligonucleotides containing either of the identified gp91-phox promoter mutations is used as a probe (lanes 5 and 6 ). The absence of the faster migrating complex appears to enhance the slower DNA/protein complex in these lanes.

\section{Discussion}

Multiple molecular defects within the coding region and introns of the gp91-phox gene can lead to X-linked CGD (15). Pre- 
Figure 7. Effect of gp91phox mutations on the association of promoter region oligonucleotides with DNA-binding proteins. Gel shift analysis was performed as described in Methods, using nuclear extract from PLB985 cells induced to differentiate along the granulocytic lineage.

Lane 1, no extract; lane 2, extract plus probe corresponding to the wild type gp91-phox promoter sequence ( -30 to 68 ); lane 3 , same as lane 2 plus addition of $20 \mathrm{ng}$ (about 1 pmol) of unlabeled competitor doublestranded oligonucleotide homologous to the probe; lane 4, same as lane 2 plus addition of $20 \mathrm{ng}$ (about $1 \mathrm{pmol}$ ) of heterologous competitor double-stranded oligonucleotide (-1 to -39 of gp91phox promoter); lane 5, extract plus oligonucleotide probe corresponding to -57 promoter mutation; lane 6 , extract plus oligonucleotide probe corresponding to -55 promoter mutation.

viously reported mutations include large, multigene deletions $(16,49)$, smaller deletions and insertions leading to frameshifts $(50)$, missense and nonsense substitutions $(18,19)$, and splicing errors $(20,21)$. However, many cases of X-linked CGD are characterized by diminished levels of gp91-phox mRNA and thus could derive from mutations in regulatory regions governing transcription of the gene (although defects in RNA processing or stability are also possible). In this study, we have identified two mutations at base pairs -55 and -57 in the gp91phox promoter region. Each is associated with X-linked CGD with diminished expression of immunoreactive protein and gp91-phox mRNA, with relative preservation of transcription initiation at an alternative start site at nucleotide 190 of the normal cDNA sequence. Each mutation abolishes the association of oligonucleotides corresponding to the gp91-phox promoter region with a DNA-binding protein detectable on gel shift assay. Hence, absence of protein binding appears to be causally related to the diminution of gp91-phox expression and to the development of CGD in patients carrying these promoter mutations.

The region of gp91-phox gene flanking sequence in which the mutations and protein binding occur lies in between the well-characterized consensus sequences of a duplicated CCAAT box and a TATA box (see Fig. 6). However, the TATA box in this promoter region does not meet minimum requirements for TATA box binding factor: $T_{82} A_{97} T_{93} A_{85}\left(A\right.$ or $T$ ) ${ }_{100} A_{83}$ (A or $T)_{100}$, where the subscript indicates the percent occurrence of the indicated nucleotide (51). Thus, it is not clear whether the partial consensus TATA box actually functions in transcription initiation by RNA polymerase II, nor whether the lack of full consensus sequence at this location contributes to the instability of the site of transcriptional initiation in the promoter region mutations.
Previous studies of the gp91-phox promoter region have identified a CCAAT displacement protein that binds to the region around the CCAAT box and interferes with CP1 binding (14). These DNA-binding proteins, CCAAT displacement factor and CP1, respectively repress and (probably) enhance gp91phox expression. The TATA box is a highly conserved sequence motif that is critical for promoter activity and initiation of transcription by RNA polymerase II (48).

As shown in the gel shift assay presented in Fig. 7, the absence of the faster migrating of the two DNA-protein complexes appears to enhance the amount of oligonucleotide bound in the slower-migrating complex. This finding suggests that these two DNA-binding proteins compete for binding. However, no firm conclusions can be reached, as the specific activity of the probes may differ. More detailed characterization of these DNA-binding proteins is in progress to address this question. The protein responsible for the faster-migrating complex is detectable in cell lines representing both myeloid and nonmyeloid hematopoietic lineages, but has not yet been found in nonhematopoietic cells (Eklund, E. A., and D. G. Skalnik, manuscript submitted for publication). Thus, further investigation will also be needed to define its role and interactions with other transcription factors in the regulation of gp91-phox and possibly other myeloid-specific genes.

The data also imply a relationship between the fine structure of the promoter region and the position for initiation of transcription, presumably mediated by the DNA-binding protein (s) that associate with the sequence mutated in these CGD kindreds. Transcription from the alternative start site, which is a barely detectable product of normal transcription, appears relatively unaffected by the mutations and hence becomes a major product in the CGD cells. Although only $190 \mathrm{nt}$ downstream from the start of the normal cDNA, the site is located in the third exon of the gp91-phox gene, so its position is actually $3.2 \mathrm{~kb}$ from the normal site in genomic DNA, due to the additional two intervening sequences of 1.9 and $1.1 \mathrm{~kb}$. Examination of the exon and intron sequence upstream from the alternative start site reveals a possible SP-1 binding site in the second intron, $45 \mathrm{nt}$ upstream from the nt 190 alternative transcription start site, but no other sequence elements associated with $5^{\prime}$ regulatory regions.

Translation of the transcript could theoretically yield a protein product lacking the normal gp91-phox amino terminal sequence, utilizing the in-frame ATG codon at position 205 (seen at the top of the marginal sequence in Fig. 4) or that at position 319 , which is associated with a Kozak consensus sequence for translational initiation (9). The lack of detection of such a polypeptide on the Western blots, such as that in Fig. 1, could indicate either instability or insufficient synthesis of such an abnormal gene product.

The connection between the molecular effects of the mutations and the cellular CGD phenotype in these kindreds remains obscure. As presented in detail elsewhere, ${ }^{2}$ the patients have a rare, "variant" form of the disease characterized by near normal expression of phagocyte oxidase activity in a small subset (5$10 \%$ ) of neutrophils and no activity in the remaining cells. We speculate that this manifestation of neutrophil heterogeneity may reflect the utilization of different DNA binding proteins for the enhancement or initiation of gp91-phox transcription by the subpopulation unaffected by the mutations.

The promoter region mutations reported in the present study extend the inventory of molecular changes responsible for CGD 
to regulatory defects that interfere with mRNA transcription. They have also served as "experiments of nature" that both demonstrate the importance of the gp91-phox promoter region sequence between the CCAAT and TATA boxes and help detect one or more previously unknown DNA-binding proteins that associate with this sequence element.

\section{Acknowledgments}

We thank Dr. Paul Siebert (Clontech, Inc.) for advice and reagents for 5'-RACE mapping; and Darlene Barnard, Mary Lively, Carolyn Padden, Julie Rae, and Constance Whitney for excellent technical assistance.

This work was supported by National Institutes of Health grants AI-33346, CA-58947, DK-41625, and HL-03130. D. G. Skalnik was supported by the American Cancer Society (JFRA 421), the National Leukemia Association, the Riley Memorial Association, and the Project Development Program, Research and Sponsored Programs, Indiana University at Indianapolis. E. A. Eklund was supported by the Walther Oncology Center.

\section{References}

1. Forrest, C. B., J. R. Forehand, R. A. Axtell, R. L. Roberts, and R. B Johnston, Jr. 1988. Clinical features and current management of chronic granulomatous disease. Hematol. Oncol. Clin. N. Am. 2:253-266.

2. Berendes, H., R. A. Bridges, and R. A. Good. 1957. A fatal granulomatosus of childhood: the clinical study of a new syndrome. Minn. Med. 40:309-312.

3. Mouy, R., A. Fischer, E. Vilmer, R. A. Seger, and C. Griscelli. 1989. Incidence, severity, and prevention of infections in chronic granulomatous disease. J. Pediatr. 114:555-560.

4. Finn, A., N. Hadzic, G. Morgan, S. Strobel, and R. J. Levinsky. 1990 Prognosis of chronic granulomatous disease. Arch. Dis. Child. 65:942-945.

5. Holmes, B., A. R. Page, and R. A. Good. 1967. Studies of the metabolic activity of leukocytes from patients with a genetic abnormality of phagocyte function. J. Clin. Invest. 46:1422-1432.

6. Curnutte, J. T., D. M. Whitten, and B. M. Babior. 1974. Defective superoxide production by granulocytes from patients with chronic granulomatous disease. N. Engl. J. Med. 290:593-597.

7. Smith, R. M., and J. T. Curnutte. 1991. Molecular basis of chronic granulomatous disease. Blood. 77:673-686.

8. Parkos, C. A., R. A. Allen, C. G. Cochrane, and A. J. Jesaitis. 1987. Purified cytochrome $b$ from human granulocyte plasma membrane is comprised of two polypeptides of relative molecular weights of 91,000 and 22,000. J. Clin. Invest. 80:732-742.

9. Royer-Pokora, B., L. M. Kunkel, A. P. Monaco, S. C. Goff, P. E. Newburger, R. L. Baehner, F. S. Cole, J. T. Curnutte, and S. H. Orkin. 1986. Cloning the gene for an inherited disorder-chronic granulomatous disease-on the basis of its chromosomal location. Nature (Lond.). 322:32-38.

10. Baehner, R. L., L. M. Kunkel, A. P. Monaco, J. L. Haines, P. M. Conneally, C. Palmer, N. Heerema, and S. H. Orkin. 1986. DNA linkage analysis of X chromosome-linked chronic granulomatous disease. Proc. Natl. Acad. Sci. USA. 83:3398-3401.

11. Mills, E. L. and P. G. Quie. 1983. Inheritance of chronic granulomatous disease. In Chronic Granulomatous Disease. J. I. Gallin and A. S. Fauci, editors. Raven Press, New York. 25-54.

12. Orkin, S. H. 1989. Molecular genetics of chronic granulomatous disease. Annu. Rev. Immunol. 7:277-307.

13. Segal, A. W., A. R. Cross, R. C. Garcia, N. Borregaard, N. H. Valerius, J. F. Soothill, and O. T. G. Jones. 1983. Absence of cytochrome $b_{-245}$ in chronic granulomatous disease. A multicenter European evaluation of its incidence and relevance. N. Engl. J. Med. 308:245-251.

14. Skalnik, D. G., E. C. Strauss, and S. H. Orkin. 1991. CCAAT displacement protein as a repressor of the myelomonocytic-specific gp91-phox gene promoter. J. Biol. Chem. 266:16736-16744.

15. Curnutte, J. T., S. H. Orkin, and M. C. Dinauer. 1994. Genetic disorders of phagocyte function. In The Molecular Basis of Blood Diseases. G. Stamatoyannopoulos, A. W. Neinhuis, P. W. Majerus, and H. Varmus, editors. W. B. Saunders, Philadelphia. 493-540.

16. Frey, D., M. Mächler, R. A. Seger, W. Schmid, and S. H. Orkin. 1988. Gene deletion in a patient with chronic granulomatous disease and McCleod syndrome: Fine-mapping of the Xk gene locus. Blood. 71:252-255.

17. De Saint-Basile, G., M. C. Bohler, A. Fischer, J. Cartron, J. L. Dufier, C. Griscelli, and S. H. Orkin. 1988. Xp21 DNA microdeletion in a patient with chronic granulomatous disease, retinitis pigmentosa, and McLeod phenotype. Hum. Genet. 80:85-89.

18. Dinauer, M. C., J. T. Curnutte, H. Rosen, and S. H. Orkin. 1989. A missense mutation in the neutrophil cytochrome $b$ heavy chain in cytochromepositive X-linked chronic granulomatous disease. J. Clin. Invest. 84:2012-2016.

19. Bolscher, B. G. J. M., M. de Boer, A. De Klein, R. S. Weening, and D. Roos. 1991. Point mutations in the $\beta$-subunit of cytochrome $b_{558}$ leading to $\mathrm{X}$ linked chronic granulomatous disease. Blood. 77:2482-2487.

20. Schapiro, B. L., P. E. Newburger, M. S. Klempner, and M. C. Dinauer. 1991. Chronic granulomatous disease presenting in a 69-year-old man. N. Engl. J. Med. 325:1786-1790.

21. de Boer, M., B. G. J. M. Bolscher, M. C. Dinauer, S. H. Orkin, C. I. E. Smith, A. Åhlin, R. S. Weening, and D. Roos. 1992. Splice site mutations are a common cause of X-linked chronic granulomatous disease. Blood. 80:1553-1558.

22. Hopkins, P. J., D. G. Skalnik, E. A. Eklund, P. E. Newburger, and J. T. Curnutte. 1992. Mutations in the gp91-phox gene promoter region result in clonal expression of cytochrome $b_{558}$ and symptomatic chronic granulomatous disease. Blood. 80 (Suppl. 1):251a.(Abstr.)

23. Lew, P. D., F. S. Southwick, T. P. Stossel, J. C. Whitin, E. R. Simons, and H. J. Cohen. 1981. A variant of chronic granulomatous disease: deficient oxidative metabolism due to a low-affinity NADPH oxidase. N. Engl. J. Med. 305:1329-1333.

24. Seger, R. A., L. Tiefenauer, T. Matsunaga, A. Wildfeuer, and P. E. Newburger. 1983. Chronic granulomatous disease due to granulocytes with abnormal NADPH oxidase activity and deficient cytochrome b. Blood. 61:423-428.

25. Borregaard, N., A. R. Cross, T. Herlin, O. T. G. Jones, A. W. Segal, and N. H. Valerius. 1983. A variant form of $X$-linked chronic granulomatous disease with normal nitroblue tetrazolium slide test and cytochrome b. Eur. J. Clin. Invest. 13:243-247.

26. Newburger, P. E., F. W. Luscinskas, T. Ryan, C. J. Beard, J. Wright, O. S. Platt, E. R. Simons, and A. I. Tauber. 1986. Variant chronic granulomatous disease: Modulation of the neutrophil defect by severe infection. Blood. 68:914919.

27. Roos, D., M. de Boer, N. Borregard, O. W. Bjerrum, N. H. Valerius, R. A. Seger, T. Mühlebach, B. H. Belohradsky, and R. S. Weening. 1992. Chronic granulomatous disease with partial deficiency of cytochrome $b_{558}$ and incomplete respiratory burst: Variants of the X-linked, cytochrome $b_{558}$-negative form of the disease. J. Leukocyte Biol. 51:164-171.

28. Woodman, R. C., P. E. Newburger, R. Erickson, and J. T. Curnutte. 1989. A new X-linked variant of chronic granulomatous disease characterized by a normal clone of phagocytic cells and an associated cytosol factor deficiency. Blood. 74 (Suppl. 1):108a.(Abstr.)

29. Dinauer, M. C., E. A. Pierce, R. W. Erickson, T. J. Muhlebach, H. Messner, S. H. Orkin, R. A. Seger, and J. T. Curnutte. 1991. Point mutation in the cytoplasmic domain of the neutrophil p22-phox cytochrome $b$ subunit is associated with a nonfunctional NADPH oxidase and chronic granulomatous disease. Proc. Natl. Acad. Sci. USA. 88:11231-11235.

30. Dinauer, M. C., S. H. Orkin, R. Brown, A. J. Jesaitis, and C. A. Parkos. 1987. The glycoprotein encoded by the $\mathrm{X}$-linked chronic granulomatous disease locus is a component of the neutrophil cytochrome b complex. Nature (Lond.). 327:717-720.

31. Curnutte, J. T., R. Kuver, and P. J. Scott. 1987. Activation of NADPH oxidase in a cell-free system. Partial purification of components and characterization of the activation process. J. Biol. Chem. 262:5563-5569.

32. Boyum, A. 1968. Isolation of mononuclear cells and granulocytes from human blood. Scand. J. Clin. Lab. Invest. 21 (Suppl. 97):1-77.

33. Ginsburg, D., R. I. Handin, D. T. Bonthron, T. A. Donlon, G. A. P. Bruns, S. A. Latt, and S. H. Orkin. 1985. Human von Willebrand factor: Isolation of complementary DNA clones and chromosomal location. Science (Wash. DC). 228:1401-1406.

34. Maniatis, T., E. F. Fritsch, and J. Sambrook. 1990. Molecular Cloning: A Laboratory Manual. Cold Spring Harbor Laboratory, Cold Spring Harbor, NY.

35. Parkos, C. A., M. C. Dinauer, L. E. Walker, R. A. Allen, A. J. Jesaitis, and S. H. Orkin. 1988. The primary structure and unique expression of the 22 kilodalton light chain of human neutrophil cytochrome b. Proc. Natl. Acad. Sci. USA. 85:3319-3323.

36. Gatti, R. A., P. Concannon, and W. Salser. 1984. Multiple use of Southern blots. Biotechniques. 2:148-155.

37. Katz, R. A., B. F. Erlanger, and R. V. Guntaka. 1983. Evidence for extensive methylation of ribosomal RNA genes in a rat XC cell line. Biochim. Biophys. Acta. 739:258-264.

38. Orita, M., H. Iwahana, H. Kanazawa, K. Hayashi, and T. Sekiya. 1989. Detection of polymorphisms of human DNA by gel electrophoresis as singlestrand conformation polymorphisms. Proc. Natl. Acad. Sci. USA. 86:2766-2770.

39. Orita, M., Y. Suzuki, T. Sekiya, and K. Hayashi. 1989. Rapid and sensitive detection of point mutations and DNA polymorphisms using the polymerase chain reaction. Genomics. 5:874-879.

40. Frohman, M. A., M. K. Dush, and G. R. Martin. 1988. Rapid production of full-length cDNAs from rare transcripts: amplification using a single genespecific oligonucleotide primer. Proc. Natl. Acad. Sci. USA. 85:8998-9002. 
41. Belyavsky, A., T. Vinogradova, and K. Rajewsky. 1989. PCR-based cDNA library construction: general cDNA libraries at the level of a few cells. Nucleic Acids Res. 17:2919-32.

42. Edwards, J. B., J. Delort, and J. Mallet. 1991. Oligodeoxyribonucleotide ligation to single-stranded cDNAs: a new tool for cloning 5' ends of mRNAs and for constructing cDNA libraries by in vitro amplification. Nucleic Acids Res. 19:5227-5232.

43. Tucker, K. A., M. B. Lilly, L. Jr. Heck, and T. A. Rado. 1987. Characterization of a new human diploid myeloid leukemia cell line (PLB-985) with granulocytic and monocytic differentiating capacity. Blood. 70:372-378.

44. Dignam, J. D., R. M. Lebovitz, and R. G. Roeder. 1983. Accurate transcription initiation by RNA polymerase II in a soluble extract from isolated mammalian nuclei. Nucleic Acids Res. 11:1475-1489.

45. Segal, A. W. 1987. Absence of both cytochrome $b_{-245}$ subunits from neutrophils in X-linked chronic granulomatous disease. Nature (Lond.). 326:88-91.

46. Volkman, D. J., E. S. Buescher, J. I. Gallin, and A. S. Fauci. 1984. B cell lines as models for inherited phagocytic diseases: superoxide generation in chronic granulomatous disease and granules in Chediak-Higashi syndrome. J. Immunol. 133:3006-3009.

47. Hirzmann, J., D. Luo, J. Hahnen, and G. Hobom. 1993. Determination of messenger RNA 5 '-ends by reverse transcription of the cap structure. Nucleic Acids Res. 21:3597-3598.

48. Alberts, B., D. Bray, J. Lewis, M. Raff, K. Roberts, and J. D. Watson. 1989. Molecular Biology of the Cell. Garland Publishing, Inc., New York. 562563.

49. Francke, U., H. D. Ochs, B. de Martinville, J. Giacolone, V. Lindgren, C. Dieteche, R. A. Pagon, M. H. Ho f ker, G. J. B. van Omnen, P. L. Pearson, and R. J. Wedgewood. 1985. Minor Xp21 chromosome deletion in a male associated with expression of Duchenne muscular dystrophy, chronic granulomatous disease, retinitis pigmentosa, and McLeod syndrome. Am. J. Hum. Genet. 37:250-267.

50. Curnutte, J. T. 1993. Chronic granulomatous disease: The solving of a clinical riddle at the molecular level. Clin. Immunol. Immunopathol. 67:S2-S15.

51. Workman, J. L., and R. G. Roeder. 1987. Binding of transcription factor TFIID to the major late promoter during in vitro nucleosome assembly potentiates subsequent initiation by RNA polymerase II. Cell. 51:613-622. 